Int. J. Morphol.,

35(2):445-451, 2017

\title{
The Anatomy for Retroperitoneal Laparoscopic Splanchnicectomy
}

\author{
La Anatomía de la Esplacnicectomía Laparoscópica Retroperitoneal
}

Minliang $\mathrm{Wu}^{1,2^{*}}$; Chaoqun $\mathrm{Ma}^{1,2^{*}}$; Jinrun Yang ${ }^{1,2}$; Xiaodan $\mathrm{Guo}^{1^{* * *}}$ \& Jiajun $\mathrm{Xu}^{1{ }^{* *}}$

WU, M.; MA, C; YANG, J.; GUO, X. \& XU, J. The anatomy for retroperitoneal laparoscopic splanchnicectomy. Int. J. Morphol., 35(2):445$451,2017$.

SUMMARY: Greater splanchnic nerves (GSNs) and lesser splanchnic nerves (LSNs) are the dominant nerves in the pain of advanced cancer patients, which provides the base of retroperitoneal laparoscopic splanchnicectomy. We dissected 25 cadavers to provide anatomic basis for the surgery. Most GSNs entered the abdominal cavity close to the medial crus of the diaphragm while most LSNs the middle one. The number of the branch varies from 1 (which was $80 \%$ ) - 3. The abdominal segment length of LSNs and GSNs was $26 \mathrm{~mm}$ and $20 \mathrm{~mm}$ respectively. The mean diameter of the nerves was about $2 \mathrm{~mm}$. The laparoscope was put through abdominal wall beneath the $12^{\text {th }}$ rib at the posterior axillary line, best angles and distances for the surgery were $50^{\circ}$ and $80-110 \mathrm{~mm}$ respectively. The anatomic parameters of splanchnic nerves in the abdominal cavity as well as the angle and distance for the retroperitoneal laparoscopic splanchnicectomy and the anatomic landmarks were presented by the study. Besides the advantages of small incision, less pain and quick recovery, the anatomic parameters provided a practicable approach for the retroperitoneal laparoscopic splanchnicectomy. anatomy.

KEY WORDS: Greater splanchnic nerve; Lesser splanchnic nerve; Retroperitoneal laparoscope; Splanchnicectomy; Clinical

\section{INTRODUCTION}

Patients with advanced carcinoma of liver, gallbladder, pancreas and stomach suffer from severe abdominal and (or) back pain, unfortunately, the optimal treatment modality for which remains unclear. Such neuropathic pain is mainly conducted by the greater splanchnic nerves (GSN) and the lesser splanchnic nerves (LSN). In the clinical practice, the traditional drug treatment turns out a poor outcome (Goodman \& Gress, 2012).

Compared with drug treatment, bilateral splanchnicectomy has been proved to be a promising therapy for complete pain relief, which has been achieved with low risk of complications (Michaels \& Draganov, 2007). Another technique, neurolytic celiac plexus block (NCPB) is claimed to be an effective method of pain control for pancreatic cancer pain, it can allow a reduction in opioid dose and an evident improvement of opioid-induced adverse effects or symptoms associated with the illness. However, this therapeutic effect lasted about four-five weeks, after which symptom intensity worsened (Mercadante et al., 2003). Moreover, the reappearance of pain in the upper visceral region after an NCPB is rather common (Mercadante \& Nicosia, 1998), and the results of repeated NCPBs are disappointing (Brown $e t$ al., 1987; Vranken et al., 2001). Meanwhile, with the widespread use of endoscopic ultrasound (EUS) (Wang et al., 2013; Mekaroonkamol et al., 2015), the splanchnicectomy can be carried out in the retroperitoneal space without opening the peritoneum. It is minimally invasive, with tiny impact on the abdominal organs, small amount of $\mathrm{CO}_{2}$ absorption, and quick recovery of gastroenteric function (Xia, 2010). More importantly, compared with the concurrent thoracoscopic splanchnicectomy, the retroperitoneal modality promises to effectively avoid the complication of pneumothorax and diaphragmatic injury (Takahashi et al., 2012).

Concerning the anatomical adjacency relation of the splanchnic nerves with kidney, and that the operations on kidney and adrenal gland performed with retroperitoneal laparoscopy have been proved effective in the clinical

1 Department of Anatomy, The Second Military medical University, Shanghai, China.

2 Firt Cadet Battalion of Navy Department, The Second Military Medical University, Shanghai, China.

* Minliang Wu and Chaoqun Ma contributed equally to this work.

** Corresponding author.

This work was supported by the Creativity and Innovation Training Program of Second Military Medical University (FH2014047). 
practice, we supposed that the incision and surgical approach of retroperitoneal laparoscopic resection of adrenal tumor could be taken for reference (Shi et al., 2014).

Besides the severe complications, the anatomic variations of the splanchnic nerves makes the current thoracoscopic splanchnicectomy fails to meet the expected satisfying therapeutic effect to some extent (Naidoo et al., 2001). And the complex anatomical adjacency structures of the splanchnic nerves and the retroperitoneal space around the kidney may explain the little clinical practice of the laparoscopy on the nerves, which requires accurate anatomic location (Wang et al.). Based on this problem, this study aimed to investigate the course of the abdominal segment of splanchnic nerves followed by observing the position they pass through the diaphragm, counting the numbers, measuring their lengths and diameters and recognizing the anatomic landmarks, to provide anatomical basis for the best surgical approach of retroperitoneal laparoscopic splanchnicectomy.

Twenty-five formalin-fixed cadavers, which included 50 sides of splanchnic nerves were selected for anatomic dissection.

\section{MATERIAL AND METHOD}

Anatomic dissections from the anterior abdomen. All dissections were performed using standard instruments (i.e., scalpels and tweezers). A right subcostal oblique skin incision was made and the skin in this area was removed. The subcutaneous layer, the muscular layer and the peritoneum in this area were then carefully removed to expose the upper peritoneal cavity. The hepatogastric ligament above the lesser curvature of the stomach was then opened. The esophagus was pulled to the left to show the aortic hiatus in the diaphragm, and on the right side, the left lobe of liver was drawn to the right. The splanchnic nerves were observed beside the diaphragm pars and on the lateral of the abdominal aorta. The abdominal segment of the nerves was carefully traced in both directions by dissection of the surrounding connective tissue. The location they passed through the diaphragm was observed, the adjacent structures of the splanchnic nerves in the abdominal cavity were recorded, the number was counted, and the length and diameter of the abdominal segment was also measured. Among them, the length of GSNs and LSNs was measured respectively from where they passed through the diaphragm to the points they entered the celiac ganglia or aorticorenal ganglia (Cai, 2005). The diameter of the GSNs and LSNs was measured in the thickest part of the nerves.
Determination of the best operative approach. To determine the best operative approach for the operation through the retroperitoneal space, an anatomic probe was used to imitate the laparoscope in the retroperitoneal splanchnicectomy to find the suitable section to carry on the operation. Based on the references of the operations on kidney and adrenal gland performed with retroperitoneal laparoscopy, the intersection of posterior axillary line and the inferior margin of the $12^{\text {th }}$ rib is defined as a center mark, the incision was made parallel with the $12^{\text {th }}$ rib, and the length of the incision was about $1.5 \mathrm{~cm}$. The subcutaneous layer, the muscular layer and fascia were blunt separated. From the caudal to the cranial, the peritoneum was carefully pushed to the anteromedial of the abdominal cavity to reach the retroperitoneal space. The homemade water sac rubber glove was placed in the space and $600 \mathrm{ml}$ gas was ejected to create the sufficient operating space (Wang et al.). The probe was put in the space through the center mark of the incision and located at the suitable operation spot for splanchnicectomy after several times of attempts. And the angles and distances of the surgical approach were measured. The angle was measured between the line of the probe and the horizontal line at the center mark (acute angle), and the distance was the length from the center mark on the skin to the operation spot where the splanchnic nerves were resected (Fig. 1).

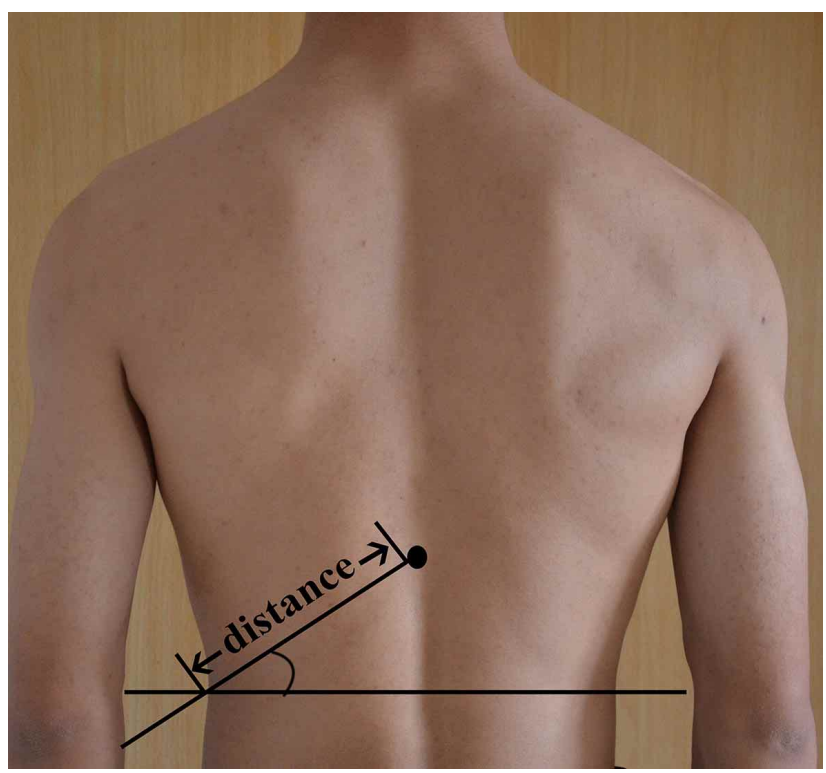

Fig.1. The angle and distance of the laparoscope to reach the splanchnic nerves in the retroperitoneal laparoscopic approach.

Layer anatomy from the post abdomen. To find the adjacent structures the laparoscope would go through in the operation, a layer anatomy from the back was carried on. Two horizontal skin incisions were made at $60 \mathrm{~mm}$ superior or inferior to the spinous processes of the first lumbar 
vertebra and two longitudinal incisions, at posterior median line and at midaxillary line. Then the skin in this area was removed. Next, the subcutaneous layer and the muscular layer in this area were carefully removed in sequence to expose the retroperitoneal space. The 12th rib was removed for better exposure. And the kidney and liver were pushed to the right. The abdominal segment of the nerves was carefully traced in both sides by dissection of the surrounding connective tissue. The structures of every layer were recorded in the dissection.

\section{RESULTS}

Anatomic dissections. According to the observation of the anterior of abdominal cavity, the adjacent structures in the upper abdomen were pulled aside to expose the axial structures, the splanchnic nerves were
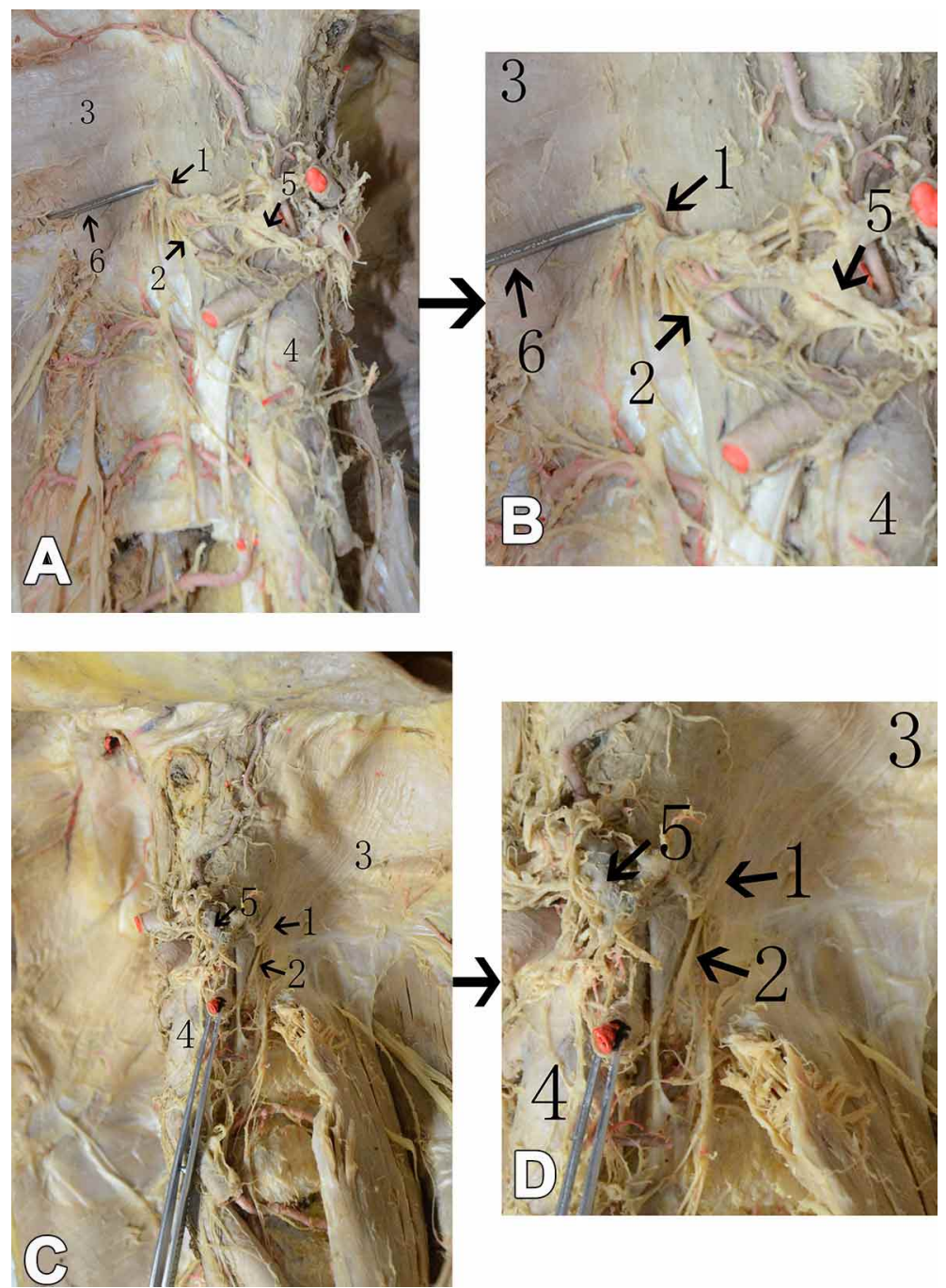

Fig. 2. The right (A and B) the left(C and D) abdominal GSN and LSN and their relationships. 1.GSN; 2.LSN; 3.diaphragm; 4.abdominal aorta; 5.celiac ganglion; 6. probe. found beside the diagram curs and on the lateral of the abdominal aorta (Fig. 2).

The positions where splanchnic nerves passed through the diaphragm. The results of dissections showed that $92.9 \%$ of the left GSN and $86.2 \%$ of the right GSN were close to the medial crus of diaphragm while $93.3 \%$ of the left LSN and $87.0 \%$ of the right LSN were close to the medial crus of diaphragm when the splanchnic nerves passed through the diaphragm. And the GSN and LSN entered the superolateral edge of the celiac ganglion and the aorticorenal ganglion respectively.

The number, length and diameter of GSN in the abdominal cavity. Among the dissected specimens, $16 \%$ of the specimens had 2 left GSNs, the other $84 \%$ had 1; $12 \%$ had 2 right GSNs, $4 \%$ had 3, and the other $84 \%$ had 1 .

The analysis of the measuring results shows that the length of the left GSN was $(14.03 \pm 7.11) \mathrm{mm}$, and the right was $(20.03 \pm 9.83) \mathrm{mm}$.

Besides, the diameter of the left GSN in the abdominal cavity was $(1.90 \pm 1.50) \mathrm{mm}$, and the right was $(2.29 \pm 0.86) \mathrm{mm}$.

The number, length and diameter of LSN in the abdominal cavity. Among the dissected specimens, $20 \%$ of the specimens had 2 left LSNs, the other $80 \%$ had $1 ; 4 \%$ had 2 right LSNs, and the other $96 \%$ had 1.

After analyzing the measuring results, it was found that the length of the left LSN was $(21.78 \pm 6.23) \mathrm{mm}$, the right was $(24.63 \pm 5.60)$ $\mathrm{mm}$.

Besides, the diameter of the left LSN in the abdominal cavity was $(1.78 \pm 1.08) \mathrm{mm}$, and the right was $(2.06 \pm 1.97) \mathrm{mm}$.

The adjacent structures of the splanchnic nerves. After a series of dissections was performed, the splanchnic nerves of both sides were found adjacent to the medial arcuate ligament of diaphragm, the adrenal gland and the crus of diaphragm. On the left side the abdominal aorta and the hemiazygos vein were close to the nerves, while on the right were 
inferior vena cava and the azygos vein. That the anatomic relationship of the splanchnic nerves is close to the adrenal gland suggest that we could imitate the surgical incision and approach of the retroperitoneal laparoscopic resection of the adrenal tumor to do this research.

Determination of the best operative approach. When the probe was put in the retroperitoneal space, the crus of diaphragm could be identified and GSN and LSN could be found between the middle and medial crus of the diaphragm.

The angle and distance for the laparoscopic splanchnicectomy. The angle of the surgical approach to resect the GSN was $(53.64 \pm 7.37)^{\circ}$ in the left side and $(51.41 \pm 7.51)^{\circ}$ in the right side. And the angle to resect the LSN was $(55.13 \pm 9.11)^{\circ}$ in the left side and $(52.11 \pm 7.22)^{\circ}$ in the right side.
The distance of the surgical approach to resect the GSN was $(95.54 \pm 16.51) \mathrm{mm}$ in the left side and $(100.70 \pm 13.32) \mathrm{mm}$ in the right side. And the distance to resect the LSN was $(93.88 \pm 19.32) \mathrm{mm}$ in the left side and $(102.98 \pm 17.02) \mathrm{mm}$ in the right side.

Anatomical structures the laparoscope goes through. As the dissection was conducted layer by layer from the back, after punching through the skin, the laparoscope could go through superficial fascia, latissimus dorsi, obliquus internus abdominis, transversus abdominis, transverse fascia and extraperitoneal fat layer and finally reached the retroperitoneal space (Fig. 3). Before reaching the splanchnic nerves, the laparoscope passed in the retroperitoneal space posterior to the descending colon (left), ascending colon (right), kidney, adrenal gland and liver (Fig. 4). The anatomical drawing shows the adjacent structures in the surgical approach to the splanchnic nerves (Fig. 5).
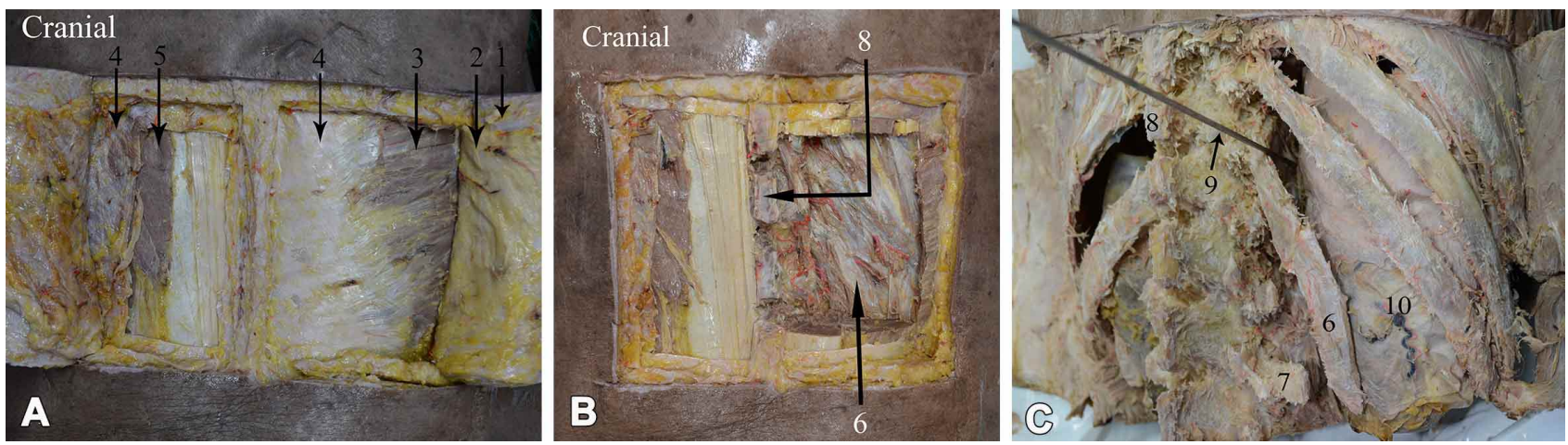

Fig. 3. Structures the laparoscope went through after punching through the skin. 1. Skin; 2. Superficial fascia; 3 . Latissimus dorsi; 4. Thoracolumber fascia; 5 . Erector spinae; $6.12^{\text {th }}$ rib; 7. Transverse process; 8 . Spinous process; 9. Probe pointing to the GSN; 10. Kidney.
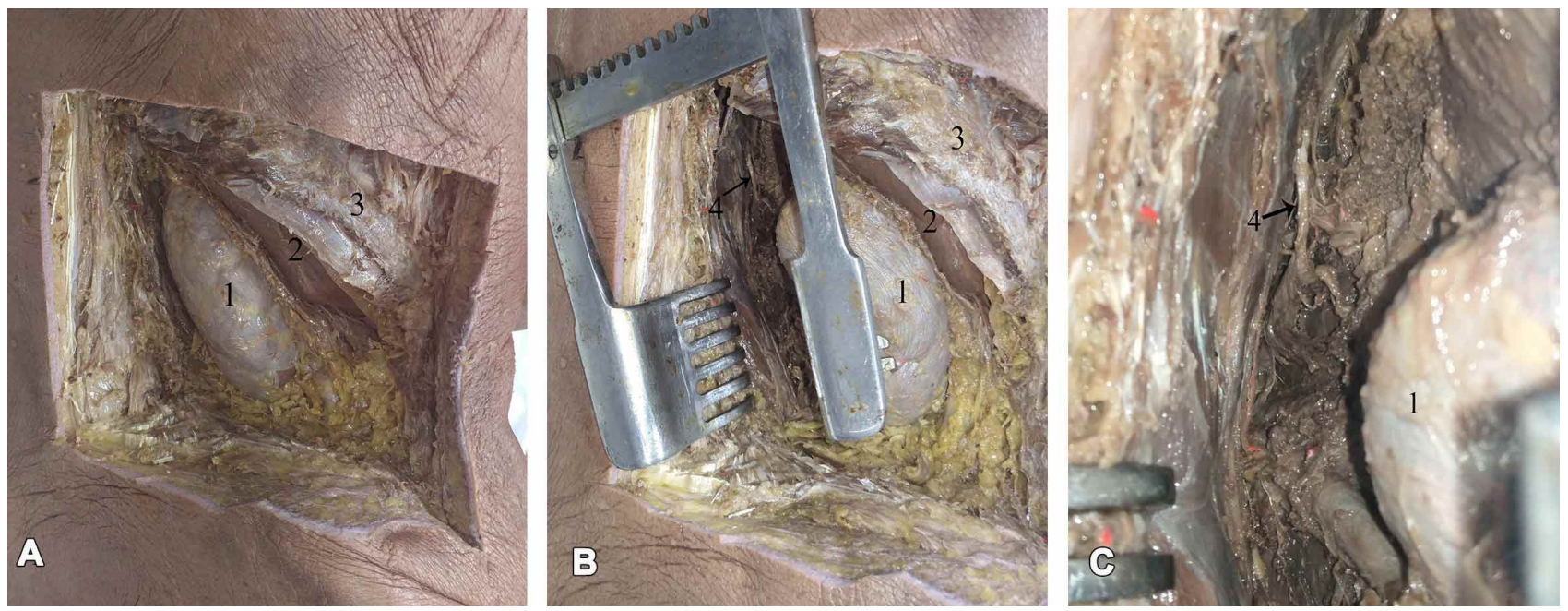

Fig. 4. Structures which the laparoscope passed by after entering the retroperitoneal space (The $12^{\text {th }}$ rib had been removed for better exposure). 1. Kidney; 2. Liver; 3. $11^{\text {th }}$ rib; 4.GSN. 


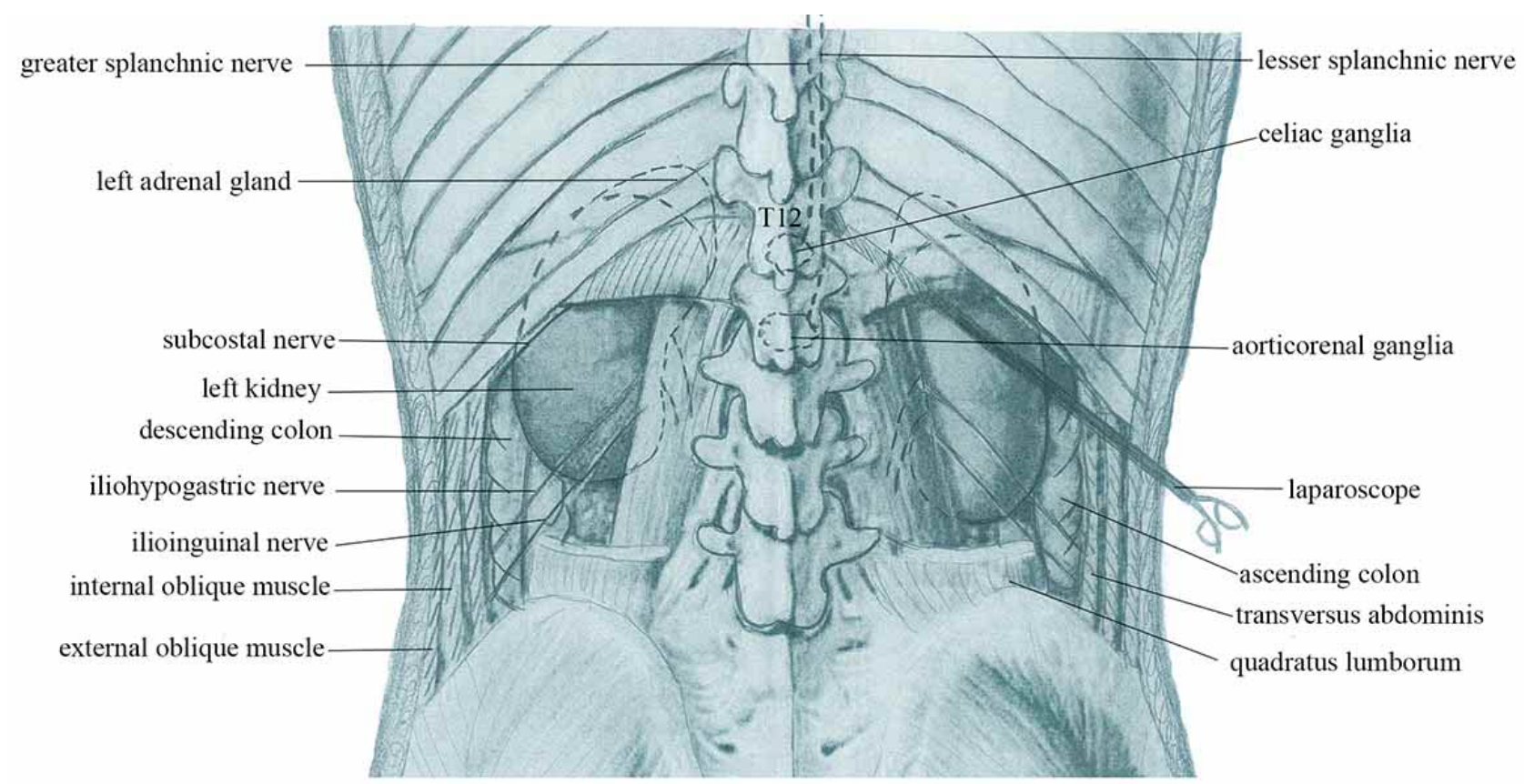

Fig. 5. The adjacent structures in the surgical approach to the splanchnic nerves.

\section{DISCUSSION}

Methods to relieve the pain of advanced cancer. Pain is the most serious clinical symptom which often contributes to the poor quality of life of the patients with advanced cancer such as liver, gallbladder, pancreas and stomach cancer. Acute pain can cause the increase of heart rate, blood pressure and blood glucose, together with the decrease of immunity. Meanwhile, it is accompanied with severe vegetative nerve dysfunction. Patients with persistent pain suffer from the vicious circle "pain-insomnia-fatigue-pain-insomnia", which, to some degree, causes depression, anxiety even suicidal tendency (Yang et al., 2013). There are many traditional methods to relieve this pain (Warshaw et al., 1998), among which the effect of analgesic drug treatment is far from satisfaction, and the percutaneous neurolytic celiac plexus block may cause many complications like gastric fistula, retroperitoneal hematoma (Chen \& Li, 1999). Though the thoracoscopic splanchnicectomy is economic, effective and minimally invasive (Masuda et al., 2014), the requirement to form artificial pneumothorax during the operation makes the procedure being forbidden for patients with serious cardiovascular diseases or severe pulmonary dysfunction (Yang et al.). Thus the retroperitoneal laparoscopic splanchnicectomy is relatively a better way with low risk of pneumothorax and diaphragmatic muscle damage.
Surgical approach and its advantages. The first step of the surgical approach was entering the retroperitoneal space from the incision on the posterior abdominal wall. Then the peritoneum was pushed to the anteromedial side with fingers to expose the retroperitoneal space. The homemade water sac rubber gloves were put in and $600 \mathrm{ml}$ gas were ejected to ensure the sufficient operating space and less injury to the adjacent structure. The laparoscope could be placed in the retroperitoneal space and the splanchnicectomy could be conducted after the GSN and LSN was found.

According to the results, firstly, to resect the LSN, the average angle for the laparoscope was about $54.62^{\circ}$ which was bigger than $52.52^{\circ}$ for the GSN, and the distance from the incision to the nerve was about $99.43 \mathrm{~mm}$, which was longer than $98.12 \mathrm{~mm}$ for the GSN. It can be explained by the fact that the position GSN passes through the diaphragm is near the medial crus of diaphragma, while the LSN's the medial diaphragmatic crus. The anatomic location of the middle diaphragmatic crus is higher than the medial diaphragmatic crus, which coincide with the results from the ventral anatomy. Secondly, compared with the right side, the angle was bigger, and the distance was shorter in the operation of the left side. The reason comes that the splanchnic nerves on the left side locate relatively lower than that on the right side. 
Thus, the difference between GSN and LSN, left side and right side should be noticed by the surgeon, meanwhile, an accurate selection of the angle and the distance is favorable for a quick and accurate positioning. In addition, to minimize the complications, the injury to the adjacent structures such as kidney, adrenal gland, colon, inferior vena cava and abdominal aorta should be avoided with the help of laparoscopic camera system (Li \& Zhou, 2009).

Anatomical basis of the splanchnicectomy. The result shows that all the GSNs and LSNs enter the retroperitoneal space between the medial and middle crus of diaphragm, among which the GSN is close to the medial crus of diaphragm and the LSN the middle crus of diaphragm. After passing through the diaphragm, the splanchnic nerves descend along the abdominal aorta before the GSN and LSN enter the celiac ganglion and the aorticorenal ganglion respectively. The nerves of both sides are adjacent to medial arcuate ligament of diaphragm, the upper pole of the adrenal gland and crus of diaphragm, together with the abdominal aorta and hemiazygos vein on left side, inferior vena cava and azygos vein on the right side. The nerves could be found according to the adjacent structures and the position they cross the diaphragm.

The amount of the nerves' abdominal segment is 1 to 3 branches, and over $80 \%$ of the specimens are one, which indicates that the operator should recognize the nerves carefully to avoid omission, including the communicating branch between the nerve trunk. As the results of both sides reveals, the average diameter of splanchnic nerves is $2.0 \mathrm{~mm}$, which makes it relatively easy to find the nerves while using the laparoscope. The average length of the abdominal segment is $20.0 \mathrm{~mm}$, which provides enough space to resect the splanchnic nerves in the laparoscopic splanchnicectomy.

Postoperative complications that may occur. Splanchnic nerve is mainly composed of the sympathetic nerve fibers and visceral pain afferent fibers, and the concomitant of the former is relatively much fewer than the latter. The sympathetic nerves originate from the ganglionated cord of T5-T12, synapse with the celiac ganglion afterwards. The post-ganglionic visceral nerves dominate the pancreas, intestinal vascular system (Bockman, 1993) and the adrenal gland (Li et al., 1999). So the broken homeostasis of the vascular system is one of the complications of the splanchnicectomy, especially for the patients with diseases of cardiovascular system. Because of the important role the splanchnic vascular bed played in blood reserving, given the splanchnicectomy may disrupt the adrenergic innervation of splanchnic vascular bed, patients may have symptoms of orthostatic hypotension after the surgery.
Besides, if the splanchnic nerve which innervates adrenal gland is resected, it may influence the function of adrenal medulla. Some articles show that when patient with splanchnicectomy is in clinostatism, the content of norepinephrine in plasma shows no obvious change, but the levels of epinephrine decreased obviously. However, when the patient is in orthostatic position, levels of norepinephrine increased significantly, while concentration of epinephrine shows almost no change (Buscher et al., 2012). In the process of treatment, the change of each system of the patients should be monitored at any time.

\section{ACKNOWLEDGEMENTS}

We are grateful to the individuals who donated their bodies after death for research and education on human anatomy without any economic benefit. We also thank their families for agreeing to the donation as well as their patience in waiting for the return of their remains after study. This work was supported by the Creativity and Innovation Training Program of Second Military Medical University (FH2014047).

WU, M.; MA, C; YANG, J.; GUO, X. \& XU, J. La anatomía de la esplacnicectomía laparoscópica retroperitoneal. Int. J. Morphol., 35(2):445-451, 2017.

RESUMEN: Los nervios esplácnicos mayores (NEM) y los nervios esplácnicos menores (NEm) son los nervios dominantes en el dolor de los pacientes con cáncer avanzado, que proporciona la base de la esplacnicectomía laparoscópica retroperitoneal. Se disecaron 25 cadáveres para proporcionar base anatómica para la cirugía. La mayoría de los NEM entraron en la cavidad abdominal cerca del pilar medial del diafragma, mientras que la mayoría de los Nem lo hicieron cerca del pilar medio. El número de ramas varía de 1 (que era del $80 \%$ ) - 3. La longitud del segmento abdominal de NEm y NEM fue de $26 \mathrm{~mm}$ y $20 \mathrm{~mm}$, respectivamente. El diámetro medio de los nervios era de aproximadamente $2 \mathrm{~mm}$. El laparoscopio se colocó a través de la pared abdominal debajo de la $12^{\mathrm{a}}$ costilla en la línea axilar posterior, los mejores ángulos y distancias para la cirugía fueron de $50^{\circ}$ y $80-110 \mathrm{~mm}$, respectivamente. Los parámetros anatómicos de los nervios esplácnicos en la cavidad abdominal, así como el ángulo y la distancia para la esplacnicectomía laparoscópica retroperitoneal y los puntos de referencia anatómicos fueron presentados por el estudio. Además de las ventajas de la incisión pequeña, menos dolor y recuperación rápida, los parámetros anatómicos proporcionaron un enfoque práctico para la esplacnicectomía laparoscópica retroperitoneal.

PALABRAS CLAVE: Nervio esplácnico mayor; Nervio esplácnico menor; Laparoscopía retroperitoneal; Esplacnicectomía; Anatomía clínica. 


\section{REFERENCES}

Bockman, D. E. Anatomy of the Pancreas. In: Go, V. L. W. (Ed.). The Exocrine Pancreas: Biology, Pathobiology and Disease. $2^{\text {nd }}$ ed. New York, Raven Press, 1993.

Brown, D. L.; Bulley, C. K. \& Quiel, E. L. Neurolytic celiac plexus block for pancreatic cancer pain. Anesth. Analg., 66(9):869-73, 1987.

Buscher, H. C.; Lenders, J. W.; Wilder-Smith, O. H.; Sweep, C. G. \& van Goor, H. Bilateral thoracoscopic splanchnicectomy for pain in patients with chronic pancreatitis impairs adrenomedullary but not noradrenergic sympathetic function. Surg. Endosc., 26(8):2183-8, 2012.

Cai, C. P. Anatomic observation of lesser splanchnic nerve. Sichuan J. Anat., (3):13-4, 2005

Chen, Y. \& Li, Y. H. The method and progress of the transdermal celiac plexus block. Int. J. Med. Radiol., 5:267-9, 1999.

Goodman, A. J. \& Gress, F. G. The endoscopic management of pain in chronic pancreatitis. Gastroenterol. Res. Pract., 2012:860-9, 2012.

Li, Q.; Johansson, H. \& Grimelius, L. Innervation of human adrenal gland and adrenal cortical lesions. Virchows Arch., 435(6):580-9, 1999.

Li, Y. M. \& Zhou, Y. Z. Nursing care of patients with renal tumor resection with laparoscope. Chin. J. Pract. Nurs., 25(5):22-3, 2009.

Masuda, T.; Kuramoto, M.; Shimada, S.; Ikeshima, S.; Yamamoto, K.; Nakamura. K. \& Baba, H. Splanchnicectomy for pancreatic cancer pain. Biomed. Res. Int., 2014:941726, 2014.

Mekaroonkamol, P.; Willingham, F. F. \& Chawla, S. Endoscopic management of pain in pancreatic cancer. J. Pancreas, 16(1):33-40, 2015.

Mercadante, S. \& Nicosia, F. Celiac plexus block: a reappraisal. Reg. Anesth. Pain Med., 23(1):37-48, 1998.

Mercadante, S.; Catala, E.; Arcuri, E. \& Casuccio, A. Celiac plexus block for pancreatic cancer pain: factors influencing pain, symptoms and quality of life. J. Pain Symptom Manage., 26(6):1140-7, 2003.

Michaels, A. J. \& Draganov, P. V. Endoscopic ultrasonography guided celiac plexus neurolysis and celiac plexus block in the management of pain due to pancreatic cancer and chronic pancreatitis. World $J$. Gastroenterol., 13(26):3575-80, 2007.

Naidoo, N.; Partab, P.; Pather, N.; Moodley, J.; Singh, B. \& Satyapal, K. S. Thoracic splanchnic nerves: implications for splanchnic denervation. J. Anat., 199(Pt. 5):585-90, 2001.

Shi, L.; Cai, W.; Dong, J.; Zhang, X.; Gao, J.; Song, T.; Sun, S.; Zu, Q. \& Wang, W. Single-port laparoscopic retroperitoneal surgery using a modified single-port device in urology. Urol. Int., 92(1):83-8, 2014.

Takahashi, R.; Furubayashi, N.; Nakamura, M. \& Hasegawa, Y. Surgical considerations of the renal fascia and the retroperitoneal space around the kidney. J. Bodyw. Mov. Ther, 16(3):392-6, 2012.

Vranken, J. H.; Zuurmond, W. W. \& de Lange, J. J. Increasing the efficacy of a celiac plexus block in patients with severe pancreatic cancer pain. J. Pain Symptom Manage., 22(5):966-77, 2001.

Wang, X.; Wu, Q.; Zeng, X.; Xiao, H.; Liu, H. \& Ji, J. Clinical analysis of 26 cases of retroperitoneally laparoscopic surgery for adrenal tumors. J. Qiqihar Univ. Med., (17):2545-6, 2013.

Warshaw, A. L.; Banks, P. A. \& Fernández-Del Castillo, C. AGA technical review: treatment of pain in chronic pancreatitis. Gastroenterology, 115(3):95-102, 1998.

Xia, M. Perioperative nursing care of patients with retroperitoneal laparoscopic adrenal tumor resection. Nurs. Pract. Res., 7:74-6, 2010.

Yang, L. W.; Liu. J. \& Yan, M. Patients suffered from pain: don't give up. Home Med., 9:19, 2013.
Corresponding author:

Dr. Jiajun Xu

Department of Anatomy

Second Military Medical University

800 Xiangyin Road

Shanghai, 200433

PR CHINA

E-mail: xujiajunsmmu@163.com

Co-Corresponding author:

Xiaodan Guo

Department of Anatomy

The Second Military Medical University

E-mail: 514672591@qq.com

First author:

Minliang Wu

Department: First Cadet Battalion of Navy Department

The Second Military Medical University

E-mail:wml9398@163.com

\section{Co-First author:}

Chaoqun $\mathrm{Ma}$

Department: First Cadet Battalion of Navy Department

The Second Military Medical University

E-mail: maria940501@outlook.com

Third author:

Jinrun Yang

Department: First Cadet Battalion of Navy Department

The Second Military Medical University

E-mail: 736303383@qq.com

Received: 20-12-2016

Accepted: 02-03-2017 